5. Rex D. K., Boland C. R., et al., "Colorectal Cancer Screening: Recommendations for Physicians and Patients from the U.S. Multi-Society Task Force on Colorectal Cancer", Am J Gastroenterol, 112(7), pp.(2017) 1016-1030.

6. Sharara AI Chalhoub JM, Beydoun M, et al, "A Customized Mobile Application in Colonoscopy
Preparation: A Randomized Controlled Trial", Clin Transl Gastroenterol, 8(1), pp.(2017) e211.

7. Walter B Schmid R, Delius Sv, "A Smartphone App for Improvement of Colonoscopy Preparation (ColoprAPP): Development and Feasibility Study", JMIR mHealth and uHealth, 5(9), pp.(2017) e138.

\title{
THỰC TRANG BÊ̂NH RĂNG MIÊNNG VÀ MộT SỐ YẾU TỐ LIÊN QUAN CỦA HỌC SINH HAI TRƯỜNG TIỂU HỌC THÀNH PHỐ ĐIÊ̂N BIÊN PHỦ, TỈNH ĐIỆN BIÊN NĂM 2018
}

\author{
Ngô Văn Mạnh ${ }^{1}$, Lê Đức Cường ${ }^{1}$, Nguyễn Trọng Việt ${ }^{2}$
}

\section{TÓM TẮT}

Mô̂t nghiên cứu cắt ngang tiến hành trên 381 hoc sinh 2 trường tiểu học trên địa bàn thành phố Điện Biên Phủ, tỉnh Điện Biên từ tháng 7/2018 đến tháng $2 / 2019$. Mục tiêu của nghiên cứu nhằm xác đinh tỷ lệ học sinh mắc các bệnh răng miệng. Kết quả nghiên cứu cho thấy: $56,4 \%$ đối tương nghiên cứu là trẻ nam, dân tộc Kinh chiếm 82,9\% tổng số đối tượng. 63,5\% hoc sinh bi sâu răng, 23,4\% hoc sinh có chỉ số vê sinh răng miệng OHI-S kém, 38,8\% có cao răng, 35,7\% có chảy máu lợi, tỷ lê viêm lợi là $16,0 \%$. Có mối liên quan giữa tình trạng chảy máu lợi và có cao răng với tình trang sâu răng với OR lần lượt là 3,84 và 3,08 . Trẻ có chỉ số GI tốt có tỷ lệ sâu răng thấp hơn trẻ có GI kém $(p<0,05)$. Có mối liển quan giữa tình trạng bệnh sâu răng và tình trạng cặn bám răng của học sinh $(p<0,05)$. Trẻ có khám răng có tỷ lê sâu răng thấp hơn trẻ không khám răng $(p<0,05)$. Trẻ ăn đồ ngọt thường xuyên có khả năng bị sâu răng cao gấp 1,67 lần so với trẻ ít ăn đồ ngọt

Tư khóa: bệnh răng miệng, các yếu tố liên quan, học sinh tiểu học

\section{SUMMARY}

PREVALENCE OF DENTAL DISEASES AND RELATED FACTORS AMONG PUPILS OF TWO PRIMARY SCHOOL IN DIEN BIEN PHU CITY, DIEN BIEN PROVINCE IN 2018

A cross-sectional study was conducted on 381 students from 2 primary schools in Dien Bien Phu city, Dien Bien province from July 2018 to February 2019. The objective of the study was to determine the percentage of pupils with dental diseases. The study results showed that: $56.4 \%$ of the study subjects were boy, the Kinh ethnic group accounted for $82.9 \%$ of the total number of subjects. $63.5 \%$ of pupils have tooth decay, $23.4 \%$ of pupils have poor OHI-S oral hygiene

${ }^{1}$ Trường Đại học Y Dược Thái Bình.

²Bênh viên đa khoa Điền Biên

Chịu trách nhiệm chính: Ngô Văn Mạnh

Email: manhsdh@gmail.com

Ngày nhận bài: 9.7.2021

Ngày phản biên khoa hoc: 6.9.2021

Ngày duyệt bài: 13.9.2021 index, $38.8 \%$ have tartar, $35.7 \%$ have bleeding gums, the rate of gingivitis is $16.0 \%$. There is a relationship between bleeding gums and tartar with dental caries with OR of 3.84 and 3.08, respectively. Children with good GI have a lower rate of dental caries than children with poor GI $(p<0.05)$. There is a relationship between the status of dental caries and the status of dental deposits of pupils $(p<0.05)$. Children with dental examination within 1 year had a lower rate of tooth decay than children without dental examination $(p<0.05)$. Children who eat sweets regularly are 1.67 times more likely to have tooth decay than children who rarely eat sweets

Key word: dental disease, related factors, primary school pupils

\section{I. ĐĂT VẤN ĐỀ}

Các bệnh răng miệng đang là vấn đề được quan tâm của toàn xã hội khi tỷ lệ người mắc ngày một tăng. Theo số liệu từ Bệnh Viện Răng Hàm Mắt Hà Nội vừa công bố, cả nước có trên $60 \%$ dẩn số mắc bệnh sâu răng, trong đó lứa tuổi từ 6 - 12 tuổi chiếm trên $85 \%$ (trung bình mỗi trẻ em lứa tuổi học đường thường có 5-6 răng sâu) [1]. Số liệu thống kê cho thấy trên $80 \%$ học sinh tiểu học Việt Nam mắc các bệnh răng miệng như sâu răng, viêm quanh răng, ở lứa tuổi lớn hơn tỉ lệ này cũng lên đến 60-70\% và có xu hướng tăng dân trong thời gian gần đây. Tỷ lê mắc bệnh răng miệng của trẻ em ở khu vực thành phố, đô thị cao hơn hẳn so với các khu vực khác. Vì đây là nhóm trẻ được vệ sinh răng miệng tốt hơn, nhưng lại là khu vực sử dụng nhiêu thức ăn ngọt như bánh kẹo các loai, đường $[2,3]$. Để góp phần giảm bớt tỷ lệ mắc các bệnh về răng miệng, cần phát hiện và điều trị sớm các trường hợp mắc bệnh và tuyên truyền giáo dục các biện pháp vê sinh răng miệng cho trẻ em. Để tìm hiểu về vẩn đề này tại thành phố Điện Biên Phủ, chúng tôi tiến hành nghiên cứu đề tài với mục tiêu tìm hiểu thực trạng mắc bệnh răng miệng và một số yếu tố 
liên quan ở học sinh hai trường tiểu học thành phố Điện Biên Phủ, tỉnh Điện Biên năm 2018 ".

\section{II. ĐỐI TƯỢNG VÀ PHƯƠNG PHÁP NGHIÊN CỨU} 2.1. Địa điểm, thời gian, đối tượng nghiên cứu

- Địa điểm nghiên cứu: được thực hiện tại 2 trường tiểu học tại thành phố Điện Biên Phủ, tỉnh Điện Biên. Bao gồm: Trường tiểu học Hà Nội và trường tiểu học Noong Bua.

- Đối tượng nghiên cứu: Học sinh của hai trường tiểu học tại địa bàn nghiên cứu. Tiêu chuẩn loại trừ: Các học sinh từ chối tham gia nghiên cứu, các học sinh vắng học tại thời điểm nghiên cứu.

- Thời gian nghiên cứu: Nghiên cứu được tiến hành từ tháng 7/2018 đến tháng 2/2019.

\subsection{Phương pháp nghiên cứu}

2.2.1. Thiết kếnghiên cứu

Nghiên cứu được thiết kế theo phương pháp mô tả thông qua cuộc điều tra cắt ngang có phân tích.

2.2.2. Cỡ mẫu và phương pháp chọn mẫu

a) Cỡ mẫu nghiên cứu

$\mathbf{n}=\mathbf{Z}_{\left(1-\frac{\alpha}{2}\right)}^{2} \times \frac{\mathbf{p}(1-\mathbf{p})}{\mathbf{d}^{2}}$

Trong đó: a: Mức ý nghĩa thống kê ( $\mathrm{a}=$ $0,05) ; Z_{(1-a / 2)}$ : Giá trị $Z$ thu được tương ứng với $a=0,05 ; Z_{(1-a / 2)}=1,96 ; d$ : Sai số tuyệt đối, trong nghiên cứu này chọn $\mathrm{d}=0,045 ; \mathrm{p}$ : tỳ lệ học sinh tiểu học mắc các bệnh răng miệng) bằng 0,77 theo nghiên cứu của Trần Tấn Tài năm 2016[4]

Thay vào công thức tính được cỡ mẫu là 336 học sinh, trên thực tế khám và điều tra: 381 học sinh.

b) Phương pháp chọn mẫu

+ Chọn trường: Lập danh sách tất cả các trường tiểu học trên địa bàn thành phố Điện Biên Phủ, tỉnh Điện Biên. Sau đó bốc thăm ngẫu nhiên 2 trường để điều tra.

+ Chọn học sinh nghiên cứu: Mỗi trường bao gồm 5 khối lớp từ lớp 1 đến lớp 5 . Tại mỗi trường tiến hành điêu tra 180 học sinh ở tất cả các khối lớp, do đó mỗi khối chọn ngẫu nhiên 1 lớp để đưa vào nghiên cứu.

Tiến hành khám răng, miệng cho toàn bộ số học sinh tại lớp được chọn

2.3. Các kỹ thuật áp dụng trong nghiên cứu

- Khám phát hiện các bệnh về răng miệng: Khám sâu răng, mất răng, răng trám, khám túi lợi và mảng bám răng.

- Khám tình trạng quanh răng qua 2 chỉ số: Chỉ số vệ sinh răng miệng đơn giản (OHI- S) và Chỉ số lợi (GI)

Công cụ thu thập thông tin: Phiếu điều tra, dụng cụ khám răng

\subsection{Một số biến số trong nghiên cứu}

- Thông tin chung về học sinh

- Thực trạng bệnh răng miệng của học sinh: tỷ lệ sau răng, tỷ lệ răng trám, tỷ lệ sâu hỗ hợp, chỉ số cao răng, chỉ số cặn bám răng, chỉ số vệ sinh răng miệng đơn giản (OHI-S), chỉ số lợi (GI)

2.5. Phương pháp xử lý số liệu. Số liệu thu thập được nhập liệu kép bằng phần mềm EpiData 3.0. Các số liệu sau khi thu thập, được tổng hợp và xử lý bằng phần mềm SPSS 22.0. Tính tỷ suất chênh OR; $95 \% \mathrm{CI}$ của OR để xác định một số yếu tố liên quan đến bệnh răng miệng của học sinh.

\section{KẾT QUẢ NGHIÊN CỨU}

3.1. Thực trạng bệnh răng miệng ở học sinh

Bảng 3.4. ì lể họ sinh bị sâu răng theo giới tính ( $n=381)$

\begin{tabular}{|c|c|c|c|}
\hline \multirow{2}{*}{ Giới Bệnh } & \multicolumn{2}{|c|}{ Sâu răng } & \multirow{2}{*}{ p } \\
\cline { 2 - 3 } & SL & \% & \\
\hline Nam & 132 & 61,4 & \multirow{2}{*}{$>0$} \\
\hline Nữ & 110 & 66,3 &, 05 \\
\hline Chung & 242 & 63,5 & \\
\hline
\end{tabular}

Tỷ lệ sâu răng ở học sinh nam là $61,4 \%$, tỷ lệ sâu răng ở nữ là $66,3 \%$, sự khác biệt này không có ý nghĩa thống kê với p>0,05

Bảng 3.2. Tình trang nha chu của hoc sinh $(n=284)$

\begin{tabular}{|c|c|c|c|c|c|c|c|}
\hline Trường & \multicolumn{2}{|c|}{$\begin{array}{l}\text { Hà Nội - Điệ̂n } \\
\text { Biên }(n=129)\end{array}$} & \multicolumn{2}{|c|}{$\begin{array}{c}\text { Noong Bua } \\
(n=155)\end{array}$} & \multicolumn{2}{|c|}{ Chung } & \multirow[t]{2}{*}{ p } \\
\hline Đặc điểm & SL & $\%$ & SL & $\%$ & SL & $\%$ & \\
\hline Chảy máu lợi & 58 & 29,4 & 78 & 42,4 & 136 & 35,7 & $<0,05$ \\
\hline Có cao răng & 71 & 36,0 & 77 & 41,8 & 148 & 38,8 & $>0,05$ \\
\hline
\end{tabular}

Bảng trên cho thấy: $35,7 \%$ học sinh có chảy máu lợi, $38,8 \%$ có cao răng, tỷ lệ chảy máu lợi ở trường tiểu học Noong Bua cao hởn trường Hà Nội- Điện Biên với $p<0,05$

Bảng 3.3. Chỉ sô GI, OHI, DI-S, cao răng ở tré

\begin{tabular}{|c|c|c|c|c|c|c|c|c|}
\hline \multirow{2}{*}{ Chí số } & \multicolumn{2}{|c|}{ GI } & \multicolumn{2}{c|}{ OHI } & \multicolumn{2}{c|}{ DI-S } & \multicolumn{2}{c|}{ CI-S } \\
\cline { 2 - 8 } & SL & \% & SL & \% & SL & \% & SL & $\%$ \\
\hline Rất tốt & 53 & 13,9 & 0 & 0 & 49 & 12,9 & 55 & 14,4 \\
\hline
\end{tabular}


VIETNAM MEDICAL JOURNAL N01 - OCTOBER - 2021

\begin{tabular}{|c|c|c|c|c|c|c|c|c|}
\hline Tốt & 155 & 40,7 & 158 & 41,5 & 143 & 37,5 & 142 & 37,3 \\
\hline Trung bình & 112 & 29,4 & 134 & 35,2 & 116 & 30,4 & 111 & 29,1 \\
\hline Kém & 61 & 16,0 & 89 & 23,3 & 73 & 19,2 & 73 & 19,2 \\
\hline Tống & $\mathbf{3 8 1}$ & $\mathbf{1 0 0}$ & $\mathbf{3 8 1}$ & $\mathbf{1 0 0}$ & $\mathbf{3 8 1}$ & $\mathbf{1 0 0}$ & $\mathbf{3 8 1}$ & $\mathbf{1 0 0}$ \\
\hline
\end{tabular}

Bảng trên cho thấy: chỉ số lợi GI ở cả 2 trường chủ yếu là tốt, chỉ có $16,0 \%$ có chỉ số GI kém; học sinh có chỉ số vệ sinh răng miệng OHI-S tốt chiếm $41,5 \%$; về tình trạng cặn bám răng của học sinh ta thấy chỉ số Dİ-S ở cả 2 trường chủ yếu là tốt, chỉ có $19,2 \%$ kém; về tình trạng cao răng của học sinh ta thấy chỉ số CI-S ở cả 2 trường chủ yếu là tốt, chỉ có 19,2\% kém

3.2. Các yếu tố liên quan tới sâu răng

Bảng 3.5 Liên quan giữa bệnh sâu răng và nha chu của học sinh (n=381)

\begin{tabular}{|c|c|c|c|c|c|c|}
\hline \multirow{2}{*}{\multicolumn{2}{|c|}{ Nha chu Bệnh }} & \multicolumn{2}{|c|}{ Sâu răng } & \multicolumn{2}{|c|}{ Không sâu răng } & \multirow{2}{*}{$\begin{array}{c}\text { OR } \\
\mathbf{C I}_{95 \%}\end{array}$} \\
\hline & & SL & $\%$ & SL & $\%$ & \\
\hline \multirow{2}{*}{ Chảy máu lợi } & Có & 111 & 45,9 & 25 & 18,0 & \multirow{2}{*}{$\begin{array}{c}3,84 \\
(2,34-6,38) \\
\end{array}$} \\
\hline & Không & 131 & 54,1 & 114 & 82,0 & \\
\hline \multirow{2}{*}{ Cao răng } & Có & 116 & 47,9 & 32 & 23,0 & \multirow{3}{*}{$\begin{array}{c}3,08 \\
(1,93-4,91)\end{array}$} \\
\hline & Không & 126 & 52,1 & 107 & 77,0 & \\
\hline & 242 & 100,0 & 139 & 100,0 & \\
\hline
\end{tabular}

Có mối liên quan giữa chảy máu lợi $(\mathrm{OR}=3,84 ; 95 \% \mathrm{CI}$ : 2,34-6,38) và có cao răng $(\mathrm{OR}=3,08$; 95\%CI: 1,93-4,91) của học sinh với tình trạng bệnh sâu răng. Nguy cơ sâu răng ở nhóm chảy máu lợi và có cao răng cao hơn rõ̃ rệt so với nhóm không bị chảy máu lợi và không có cao răng.

Bảng 3.6. Liên quan gîứa sâu răng và chải răng hàng ngày $(n=381)$

\begin{tabular}{|c|c|c|c|c|c|}
\hline \multirow{2}{*}{ Chại rănh } & \multicolumn{2}{|c|}{ Sâu răng } & \multicolumn{2}{c|}{ Không sâu răng } & \multirow{2}{*}{ OR } \\
\cline { 2 - 5 } & $\mathbf{S L}$ & $\mathbf{0}$ & $\mathbf{S L}$ & $\mathbf{0}$ & CI95\% \\
\hline Chải răng hàng ngày & 236 & 63,1 & 138 & 36,9 & 0,29 \\
\hline Không chải răng hàng ngày & 6 & 85,7 & 1 & 14,3 & $(0,03-2,39)$ \\
\hline Tống & $\mathbf{2 4 2}$ & $\mathbf{1 0 0 , 0}$ & $\mathbf{1 3 9}$ & $\mathbf{1 0 0 , 0}$ & \\
\hline
\end{tabular}

Bảng trên cho thấy trong nhóm học sinh có chải răng hàng ngày có $63,1 \%$ học sinh mắc sâu răng, tỉ lệ này ở nhóm không chải răng hàng ngày là $85,5 \%$. Tuy nhiên sự khác biệt không có ý nghĩ̃a thống kê.

Bảng 3.7. Liên quan giữa sâu răng và khám răng trong năm (n=381)

\begin{tabular}{|c|c|c|c|c|c|}
\hline Bhệnh & \multicolumn{2}{|c|}{ Sâu răng } & \multicolumn{2}{c|}{ Không sâu răng } & \multirow{2}{*}{ OR } \\
\cline { 2 - 5 } Khám răng & SL & $\%$ & SL & $\%$ & CI \\
\hline Có khám răng & 200 & 60,4 & 131 & 39,6 & 0,29 \\
\hline Không khám răng & 42 & 84,0 & 8 & 16,0 & $(0,13-0,64)$ \\
\hline Tống & $\mathbf{2 4 2}$ & $\mathbf{1 0 0 , 0}$ & $\mathbf{1 3 9}$ & $\mathbf{1 0 0 , 0}$ & \\
\hline
\end{tabular}

Bảng trêncho thấy trong nhóm có khám răng trong năm qua có $40,4 \%$ mắc sâu răng trong khi ở nhóm học sinh không đi khám răng tỉ lệ này là $84,0 \%$. Giá trị $\mathrm{OR}=0,29$

Bảng 3.8. Liên quan giữa sâu răng và mức độ thường xuyên ăn đồ ngọt ( $n=381)$

\begin{tabular}{|c|c|c|c|c|c|}
\hline \multirow{2}{*}{ Ăn độnh ngột } & \multicolumn{2}{|c|}{ Sâu răng } & \multicolumn{2}{c|}{ Không sâu răng } & \multirow{2}{*}{ OR } \\
\cline { 2 - 5 } & $\mathbf{S L}$ & $\mathbf{\%}$ & $\mathbf{S L}$ & $\mathbf{\%}$ & CI \\
\hline Thường xuyên & 171 & 67,6 & 82 & 32,4 & 1,67 \\
\hline Không thường xuyên & 71 & 55,5 & 57 & 44,5 & $(1,08-2,59)$ \\
\hline Tống & $\mathbf{2 4 2}$ & $\mathbf{1 0 0 , 0}$ & $\mathbf{1 3 9}$ & $\mathbf{1 0 0 , 0}$ & \\
\hline
\end{tabular}

Nguy cơ sâu răng ở nhóm học sinh thường xuyên ăn đồ ngọt cao hơn rõ rệt so với nhóm không thường xuyên ăn đồ ngọt ( $\mathrm{OR}=1,67$ và khoảng tin cậy $95 \%$ của $\mathrm{OR}: 1,08-2,59$ ).

\section{BÀN LUÂ̂N}

3.1. Thực trạng bệnh răng miệng ở học sinh tiểu học. Kết quả nghiên cứu cho thấy tỉ lệ sâu răng của các em học sinh tham gia nghiên cứu là khá cao, chiếm tới 63,5\%. Tỉ lệ này tương đồng với kết quả nghiên cứu ở các địa phương khác như tại tỉnh Yên Bái của Nguyễn Ngọc Nghĩa năm 2009 (62,75\%) [5]. Đăc biệt có nghiên cứu của Nguyễn Văn Tiến trển 200 em học sinh tiểu học tại huyện Kiến Xương, tỉnh Thái Bình năm 2017 [3] cho thấy tỉ lệ sâu răng lên tới $82 \%$. Những con số này đều tương đối cao, báo động về thực trạng sâu răng của học sinh tiểu học, đặc biệt tî lệ này ở các địa phương vùng đồng bằng như Thái Bình cao hơn so với các địa phương vùng cao như Điện Biên, Yên Bái

Bên cạnh sâu răng, nghiên cứu của chúng tôi cũng đánh giá tình trạng nha chu và tình trạng 
viêm lợi của học sinh. Kết quả cho thấy tỉ lệ học sinh có chảy máu lợi ở cả hai trường là 35,7\%. Theo điều tra sức khỏe răng miệng toàn quốc 2001, bệnh quanh răng ở trẻ em 6- 8 tuổi là 42,7\%; ở 9- 11 tuổi là 69,2\%; ở 12-14 tuổi là $71,4 \%$ và $15-17$ tuổi là $66,9 \%$. Như vậy, tỷ lệ bệnh quanh răng nhìn chung có chiều hướng tăng theo độ tuổi tăng dần [6].

Kết quả nghiên cứu của chúng tôi cho thấy 2 trường tiểu học có tî lệ chỉ số GI rất tốt và tốt $54,6 \%$. Cũ̃ng đánh giá về chỉ số GI, nghiên cứu của Nguyễn Hữu Thiện [7] tại trường tiểu học Kỳ Bá và trường tiểu học Vũ Lạc, tỉnh Thái Bình cho thấy hầu hết các em học sinh có chỉ số GI đạt loại tốt trở lên $(99,5 \%$ và $84,3 \%)$ tỉ lệ này cao hớn nhiều so với kết quả trong nghiên cứu của chúng tôi.

3.2. Các yếu tố liên quan tới sâu răng ở học sinh tiểu học. Trong nghiên cứu này chúng tôi thấy có mối liên quan giữa chảy máu lợi $(\mathrm{OR}=3,84 ; 95 \% \mathrm{CI}: 2,34-6,38)$ và có cao răng ( $\mathrm{OR}=3,08 ; 95 \% \mathrm{CI}: 1,93-4,91)$ của học sinh với tình trạng bệnh sâu răng. Nguy cơ sâu răng ở nhóm chảy máu lợi và có cao răng cao hơn rõ rệt so với nhóm không bị chảy máu lợi và không có cao răng. có mối liên quan giữa chỉ số GI (dùng để đánh giá tình trạng viêm lợi của học sinh) với tình trạng bệnh sâu răng của học sinh $(p<0,05)$. Tỷ lệ sâu răng ở những đối tượng có chỉ số GI ở mức rất tốt thấp hơn nhiều so với ở mức trung bình và kém $(1,7 \%$ so với $35,1 \%$ và $21,9 \%)$. Bên cạnh đó, nghiên cứu cũng chỉ ra được có mối liển quan giữa tình trạng bệnh sâu răng và tình trạng cặn bám răng của học sinh. Điêu này cho thấy các bệnh răng miệng có liên quan mật thiết với nhau.

Đánh giá mối liên quan giữa tỉ lệ sâu răng và số lần đi khám răng trong năm, kểt quả nghiên cứu của chúng tôi cho thấy trong nhóm học sinh có đi khám răng trong 1 năm qua thì có $60,4 \%$ học sinh bị sâu răng, trong khi trong nhóm học sinh không đi khám răng trong năm qua thì có tới $84 \%$ học sinh bị sâu răng. Kết quả cho thây tỉ lệ sâu răng ở nhóm học sinh không đi khám răng trong năm qua cao hớn so với tỉ lệ này ở nhóm học sinh có đi khám răng trong năm qua. Tuy nhiên, trong nghiên cứu của tác giả Deepa Gurunathan và cộng sự nghiên cứu về kiến thức, thái độ và thực hành của các bà mẹ liên quan đến Vệ sinh rắng miệng cho học sinh tiểu học tại Ấn khổng có sự khác biệt giữa số lần khám răng và bệnh sâu răng với $p>0,05[8]$.

Về thói quen thường xuyên ăn đồ ngọt với tỉ lệ sâu răng, kết quả nghiên cứu của chúng tôi chỉ ra rằng trong nhóm học sinh thường xuyên ăn đồ ngọt có $67,7 \%$ số học sinh bị sâu răng trong kho đó nhóm không thường xuyên ăn đồ ngọt có $55,5 \%$ số học sinh mắc bệnh này. Có thể thẩy nhóm học sinh có thói quen thường xuyên ăn đồ ngọt có nguy cơ mắc sâu răng cao hơn so với nhóm không thường xuyên ăn đồ ngọt $(\mathrm{OR}=1,67 ; 95 \% \mathrm{CI}: 1,08-2,59)$. Kết quả này cũng tương tự với kết quả nghiên cứu của Bùi Thanh Hải tại Hòa Bình năm 2014 [9].

\section{KẾT LUÂN}

Tỷ lệ sâu răng ở học sinh tiểu học là rất cao $63,5 \%$. Có mối liên quan giữa tình trạng chảy máu lợi và có cao răng với tình trạng sâu răng. Trẻ có chỉ số GI tốt có tỷ lệ sâu răng thấp hơn trẻ có GI kém. Có mối liên quan giữa tình trạng bệnh sâu răng và tình trạng cặn bám răng. Trẻ có khám răng có tỷ lệ sâu rằng thấp hơn trẻ không khám răng. Trẻ ằn đồ ngọt thường xuyên có khả năng bị sâu răng cao. Cần tập trung nhiêu hơn nữa vào chương trình nha học đường để thay đổi kiến thức và thực hành chăm sóc răng miệng cho trê.

\section{TÀI LIỆU THAM KHẢO}

1. Viện Răng Hàm Mă̆t Hà Nội, Báo cáo tổng kết hô̂i nghị nha học đường hàng năm các tỉnh phía Bằc. 2005.

2. Nguyễn Thanh Thủy, Thực trạng bệnh sâu răng và một số yếu tố liên quản ở học sinh tiểu học Nhật Tân, Hà nội". Tạp chí Y tế Cồng cộng, 2009. 26: p. 5-14.

3. Nguyễn Vằn Tiến, Thực trạng bệnh sâu răng và mốt số yếu tố liên quan ở học sinh trướng Tiểu học Vữ Thắng, huyện Kiến Xương, tỉnh Thái Bình năm 2017. 2017, Trường Đại học Y Y Dược Thái Bình.

4. Trần Tấn Tài, Thực trạng bệnh sâu răng và hiệu quả của giải pháp can thiệp công đồng của học sinh tại một số trường tiểu học ở Thửa Thiên Huế. 2016, Trường Đại họ Y Dược Huế.

5. Nguyê̂n Ngọc Nghĩã, Thực trạng kiến thức, thái độ, thực hành trong phòng bệnh răng miệng của học sinh tiểu hoc người Mông, tỉnh Yên Bái. Tap chí Khoa học \& Cồng nghệ, 2011. 115(1): p. 163-168.

6. Trân Văn Trường, Điêuu tra sức khỏe răng miệng toàn quốc năm 2011. 2011: NXB Y học.

7. Nguyển Hữu Thiện, Kiến thức, thái độ, thực hành chăm sóc răng miệng và kết quả hướng dẩn chải răng ở học sinh lớp 4 taii hai trường Tiểu học thành phố Thái Bình, năm 2016. 2016, Trường Đại học Y Dược Thái Bình.

8. Joyson Moses Deepa Gurunathan, Shanmugaavel $\mathrm{K}$ Arunachalam Knowledge, Attitude, and Practice of Mothers regarding Oral Hygiene of Primary School children in Chennai, Tamil Nadu, India. International Journal of Clinical Pediatric Dentistry, 2018. 11(4): p. 338-343.

9. Bùi Thanh Hải, Thực trạng bênh sâu răng và các yếu tố liên quan ở học sinh trường tiểu hợc xã Mãn Đức, huyện Tân Lạc, tỉnh Hòa Bình nằm 2014. 2014, Đại học Y Dược Thái Bình. 